\title{
The effects of acoustic disruption on short term memory
}

MARGARET NEWELL, SIR GEORGE WILLIAM'S UNIVERSITY, Montreal 25, Canada

Forty-six, 10 and 11 year old children in grade five remembered significantly fewer letters from sets of five consonants after hearing an acoustic disturbance during a five sec retention interval than under normally quiet conditions. Their short term memory was effected significantly more by a scream than by a tone.

Two prevalent theories for explaining short term memory (STM). The trace comparison theory (TC) states that the degree of forgetting is a function of the relative strength of the stored trace as compared with other previously stored, similar traces at the moment of recall. The acid bath theory (AB) states that interfering stimuli interact with the trace spontaneously during the retention interval to weaken its strength as a stored item. Interference effects can be eliminated when full capacity is available for rehearsal. Additionally, stored items lose precision of information over time (Posner \& Konuk, 1966).

The above experiment on the effects of interference on STM indicates that the locus of interference is in the retention interval itself (AB) rather than at the time of recall (TC). By presentation of similar sounding letters of varying lengths to cause acoustic confusion during the retention interval, the trace can be destroyed not only as a function of time but also as a function of the number and similarity of stored items.

Holmes \& Trollope (1967) found that massive cortical and subcortical discharge from electrical shock disrupts in some way recent memory but not older more consolidated memory. Also Lee Teng (1967) found that electroconvulsive shock disrupts the process of memory consolidation. Question was raised about the amount of shock required to give this effect and suggestion made that it could be considerably less.

By introducing disrupting acoustic stimulation to the $S$ during the retention interval of an assigned recall task, this experiment is designed to test the AB Theory for STM. In addition it is designed to test whether acoustic shock in the form of a scream is sufficient to disrupt the process of memory consolidation.

Subjects. Forty-six, grade five children (10 and 11 years old) from Lakeside Heights Elementary School were used. One group of 22 received a tone as the acoustic disturbance (Group T) and one group of 24 received a scream (Group S).

Apparatus. A tape recorder was used with a tape of 15 sets of five consonants. Five letters were presented at $.5 \mathrm{sec}$ intervals, followed by a $5 \mathrm{sec}$ silence, then the word recall and a $10 \mathrm{sec}$ silence to allow written recall. Immediately on termination of the 15 th set there followed a $5 \mathrm{sec}$ tone of $+4 \mathrm{~dB}$ for Group $\mathrm{T}$ or $5 \mathrm{sec}$ scream of +12 to $+17 \mathrm{~dB}$ (with speaker's voice measured at $0 \mathrm{~dB}$ ) for Group $S$, then: recall, a 10 sec silence and thank you to end the tape.

Procedure. After distribution of recall forms Ss were instructed accordingly:

"You will hear my voice read five letters, there will be a $5 \mathrm{sec}$ pause then my voice will say, recall. You will then have time to write down as many letters as you can remember. This will be repeated many times. If you get mixed up, never mind, just go on to the next set. Be patient and try your best until the tape is

\begin{tabular}{lcccc} 
& & Table 1 \\
& & & \\
& & & & \\
Results & & df & $t$ \\
\hline T (tone) & Normal $\bar{X}$ & Disruption $\bar{X}$ & 21 & $5.93^{*}$ \\
S (scream) & 4.0 & 3.3 & 23 & $10.6^{*}$ \\
S vs T & 4.2 & 1.5 & 44 & $4.38^{*}$ \\
\hline
\end{tabular}

${ }^{*} p<.001$

finished. Please don't peek or guess because then I won't be able to learn which letters you remember best. We will have a few practices before we begin."

The tape was run through the first four sets of letters, stopped and any questions answered. Then after "ready," the rest of the tape was heard. Group T heard the tone and Group S the scream at the end of their 15 th set.

The papers were gathered, the purpose of tone or scream explained and the Ss were thanked and rewarded with a chocolate bar.

Results. For Group $\mathrm{T}$ the mean recall without the disnupting tone was significantly higher, $p<.001$, than the mean recall with the tone. Similarily, Group $S$ recall without the scream was significantly higher, $p<.001$, than with the scream. Court's t test for correlated mean differences was used for both.

Group T scored significantly higher than Group $S, p<.001$, on recall using court's t test for uncorrelated means.

Conclusion. Through disruption of the rehearsal opportunity the competing stimuli, the scream or tone, interacted spontaneously with the trace being stored during the retention interval. The consequent weakness or complete obliteration of the stored trace suggests interference with the storage mechanism. Both the acoustic disruptions had a significant effect on STM. These results tend to reinforce the $\mathrm{AB}$ theory.

The variation in the results between the tone and scream could be explained by the ability of some to block out moderate disturbances i.e., the tone, while concentrating on set rehearsal. The acoustic disruption level of the tone was high enough to interfere only moderately with trace storage in comparison to the interference of the scream.

The severe effect of the scream on STM suggest that massive cortical and subcortical discharge from shock disrupts in some way recent memory (Holmes \& Trollope, 1967; Lee Teng, 1967). The amount of retention seems to vary directly with the amount of disruption. The ultimate amount required for complete STM eradication may vary with individuals. That acoustic shock was sufficient for significant results indicates previous types and levels of shock used may have been unduly severe (Lee Teng, 1967).

REFERENCES

HOLMES, J. E., \& TROLLOPE M. L. Effects of electroanasthesia on the memory of the rat. Proceedings of the 75th annual convention of the American Psychological Association, 1967, 2, 55-56.

POSNER, M. I., \& KONUK, A. F. On the role of interference in short term retention. J. exp. Psychol, 1966, 72 (2), 221-231.

TENG, LEE E. Retrograde amnesia in relation to current intensity and seizure pattern in chicks. Proceedings of the 75th annual convention of the American Psychological Association, 1967, 2, 87-88. 